\title{
Process intensification of membrane system for crude palm oil pretreatment
}

\begin{abstract}
The pretreatment of crude palm oil (CPO) samples with the aim of moving from the usual huge refinery plant to a more process integrated membrane module at ultrascale size was studied. The study was carried out using conventional refining, microfiltration, and ultrafiltration processes. Reduction of phosphorus fur the membrane-permeate of $43.3 \%$ was higher than that of bleached oil of $34.4 \%$. The results show that the average slurry volume after about 22-min runs for membrane with ore size of $0.45 \mu \mathrm{m}, 0.2 \mu \mathrm{m}, 50 \mathrm{~nm}$ and $20 \mathrm{~nm}$, and the average slurry volumes are $0.05,0.09,0.13$, and $0.18 \mathrm{~m} 3$ respectively.
\end{abstract}

Keyword: Ceramic materials; Heat treatment; Microfiltration; Phosphorus; Pore size; Slurries; Ultrafiltration; Ceramic membranes; Crude palm oils; Membrane systems; Miniaturization; Crude petroleum 